\title{
A rapid, PCR based test for differential molecular diagnosis of Prader-Willi and Angelman syndromes
}

\author{
Kokila A Chotai, Stewart J Payne
}

\begin{abstract}
Approximately $\mathbf{9 8 \%}$ of Prader-Willi syndrome (PWS) and $80 \%$ of Angelman syndrome (AS) cases have deletions at a common region in chromosome 15q11-13, uniparental disomy for chromosomes 15 (UPD15), or mutations affecting gene expression in this region. The resulting clinical phenotype (PWS or AS) in each class of mutation depends upon the parent of origin. Both disorders are characterised at the molecular level by abnormal methylation of imprinted genes at 15q11q13 including the small nuclear ribonucleoprotein $\mathbf{N}$ gene (SNRPN). Current diagnostic strategies include high resolution cytogenetics, fluorescence in situ hybridisation (FISH), Southern blot hybridisation, or microsatellite typing.

We have developed a novel and rapid diagnostic test for PWS and AS based on differential digestion of expressed (paternally imprinted) SNRPN sequences by the methylation sensitive endonuclease NotI or repressed (maternally imprinted) SNRPN sequences by the methylation requiring nuclease $M c r B C$, followed by PCR amplification of the SNRPN promoter. We have evaluated this test by blinded analysis of 60 characterised DNA samples (20 PWS, 20 AS, and 20 unaffected controls). SNRPN sequences could not be amplified from PWS patient DNA which had been digested with $M c r B C$, nor from AS patient DNA which had been digested with NotI. We were able to make a correct diagnosis of PWS, AS, or unaffected in all 60 samples tested. This novel test is rapid and has a high specificity and sensitivity for deletion and UPD15 cases. These features make this new test suitable as the initial step in a molecular diagnostic strategy for PWS/AS. $(\mp$ Med Genet 1998;35:472-475)
\end{abstract}

Kennedy-Galton
Centre for Medical and Community Genetics, Northwick Park and St Mark's NHS Trust, Watford Road, Harrow, Middlesex HA1 3UJ, UK

K A Chotai

S J Payne

Correspondence to:

Dr Payne.

Received 4 August 1997 Revised version accepted for publication 12 December 1997 Prader-Willi syndrome (PWS) and Angelman syndrome (AS) are complex and distinct mental retardation syndromes caused by genetic lesions in a common chromosomal region, $15 \mathrm{q} 11-\mathrm{q} 13 .{ }^{12}$ The characteristic PWS phenotype includes short stature, sexual infantilism, hypotonia, mild to moderate mental retardation and behavioural problems, characteristic facies, hyperphagia leading to obesity, and a tendency to diabetes in adolescence. ${ }^{23}$ AS presents with a distinct phenotype including severe mental retardation, characteristic facial appearance with protruding tongue and inappropriate laughter, ataxic gait, microcephaly, seizures, little or absent speech, and jerky movements. ${ }^{14}$ Both syndromes can be difficult to diagnose clinically.

Approximately $70 \%$ of PWS and AS have deletions in a common region of 15q11-13 either on the paternal chromosome in PWS or the maternal chromosome in AS. ${ }^{25}$ Approximately $28 \%$ of PWS and $3-5 \%$ of AS cases are caused by uniparental disomy at chromosome 15 (UPD15, inheriting two normal copies of chromosome 15 from only one parent). ${ }^{6} \mathrm{PWS}$ patients are disomic for maternal chromosomes 15 and AS patients disomic for paternal chromosomes $15 .{ }^{4} 7 \mathrm{~A}$ small proportion (approximately $1 \%$ of PWS and $4 \%$ of AS) have neither deletions nor disomy, but abnormal patterns of methylation at loci in 15q11-q13 ("imprinting" mutations). ${ }^{8-11}$ Rare PWS and AS patients have cytogenetically visible chromosome rearrangements involving $15 \mathrm{q} 11-\mathrm{q} 13 .{ }^{12}$ At least some of the $20 \%$ or so non-deletion, non-UPD15, normally methylated, and cytogenetically normal AS patients have mutations in the E6-AP ubiquitin-protein ligase gene (UBE3A). ${ }^{13}{ }^{14}$ It is important to be able to distinguish the molecular pathology in PWS/AS for counselling purposes since a significant recurrence risk is associated with imprinting mutations, chromosomal translocations, and UBE3A mutations, but not with deletions and UPD.

Genes at 15q11-q13 show parent of origin specific expression patterns ("imprints"). PWS/AS caused by deletion, UPD15, or abnormal methylation is characterised by abnormal expression of imprinted genes. The gene for the small nuclear ribonucleoprotein polypeptide N (SNRPN) is the best characterised imprinted gene from this region ${ }^{9} 10{ }^{15}$ and is a useful diagnostic marker for PWS and AS. ${ }^{16}$ PWS patients have only a maternal SNRPN imprint (methylated and inactivated) and AS patients have only a paternal SNRPN imprint (unmethylated and expressed).

A variety of complementary cytogenetic and PWS and AS, including high resolution cytogenetic analysis, fluorescent in situ hybridisation (FISH), methylation analysis by Southern blot hybridisation, and deletion/UPD analysis by microsatellite typing. Each technique has its own advantages and limitations. ${ }^{6}$ 


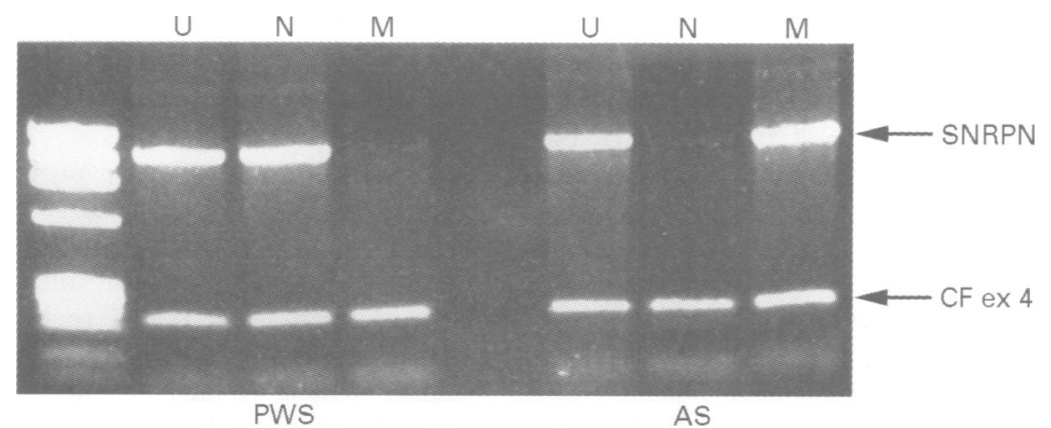

Figure 1 Molecular diagnosis of PWS and AS. Ethidium bromide stained agarose gel showing PCR products from PWS or AS DNA either undigested (U) or following NotI $(N)$ or $M c r B C(M)$ restriction digestion. The $1088 \mathrm{bp} S N R P N$ product is absent following $M c r B C$ digestion (track 4) or NotI digestion (track 6) confirming diagnosis of PWS and $A S$ respectively. The CFTR exon 4 amplification control is present in all tracks as expected. Track 1 contains molecular weight markers.

Diagnostic method(s) of choice will depend upon local resources and expertise but many molecular genetics laboratories use a strategy in which the first step is to screen for deletions, disomy, or imprinting mutations by restriction digestion with methylation sensitive endonucleases followed by Southern blot hybridisation to probes such as PW71b (D15S63) or SNRPN. ${ }^{16}{ }^{17}$

Novel PCR based diagnostic tests for PWS and AS have recently been reported. Wevrick and Francke ${ }^{18}$ reported an assay for PWS only based on RT-PCR analysis to determine expression levels of SNRPN and two other groups independently reported assays based on modification of unmethylated DNA by sodium bisulphite before allele specific amplification of SNRPN sequences. ${ }^{19} 20$

We present another novel test for SNRPN methylation status using differential restriction endonuclease digestion of genomic DNA and PCR. This strategy uses either NotI to digest unmethylated (paternally imprinted) DNA or $M c r B C$ to digest methylated (maternally imprinted) DNA followed by PCR amplification of the promoter and first exon of SNRPN to diagnose AS or PWS respectively.

\section{Methods}

PATIENTS

Twenty subjects, mostly from North Thames, were referred with a strong or suspected clinical diagnosis of PWS. Mean age at referral was 10 years (range 9 months to 49 years). Twenty patients from the same region were referred with suspected AS. Mean age at referral was 10 years (range 3 months to 39 years). In each case, molecular genetic analysis was requested to confirm the clinical diagnosis. Normal control DNA samples were from healthy members of the department and anonymised.

The diagnosis in each affected patient had been confirmed previously by Southern blot methylation analysis using probes at either D15S63 (PW71b) or SNRPN. UPD15 had been confirmed in $3 / 20$ PWS and $2 / 20$ AS patients by microsatellite analysis of the affected child and both parents.

PCR BASED METHYLATION ANALYSIS

Genomic DNA (approximately $500 \mathrm{ng}$ ) was digested with either NotI (20 units in a $20 \mu \mathrm{l}$ reaction volume) or $M c r B C$ ( 10 units in a $10 \mu \mathrm{l}$ reaction volume) according to the manufacturer's instructions (New England Biolabs), but with additional GTP (to $2 \mathrm{mmol} / \mathrm{l}$ ) and BSA (to $100 \mu \mathrm{g} / \mathrm{ml}$ ) in the $M c r B C$ reaction buffer. DNA was digested at $37^{\circ} \mathrm{C}$ overnight, followed by inactivation at $65^{\circ} \mathrm{C}$ for 20 minutes before PCR amplification.

PCR amplification was performed on $100 \mathrm{ng}$ DNA either undigested (amplification control) or digested with NotI or McrBC. PCR included both "diagnostic" primers $\mathrm{S} 1$ and $\mathrm{S} 2$ (to amplify a 1088 bp fragment containing the SNRPN promotor and exon 1), and "amplification control" primers $\mathrm{C} 1$ and $\mathrm{C} 2$ (to amplify a $300 \mathrm{bp}$ fragment of exon 4 of the CFTR gene). Primer sequences were: S1 (sense) 5'-AGGTCATTCCGGTGAGGGAGG-3'; S2 (antisense) 5'-CCCCTCCTCTAGACAGCA ATGAT-3'; C1 (sense) 5'-CTATGACCCGGA TAACAAGGAGGAGC-3'; C2 (antisense) 5'AGAATATATGTGCC ATGGGGCCTGTG3'. Each $50 \mu \mathrm{l}$ reaction contained $0.1 \mu \mathrm{mol} / 1$ of each primer in $10 \mathrm{mmol} / 1$ Tris- $\mathrm{HCl}(\mathrm{pH} \mathrm{8.3)}, 50$ $\mathrm{mmol} / 1 \mathrm{KCl}, 1.0 \mathrm{mmol} / \mathrm{l} \mathrm{MgCl}_{2}, 200 \mu \mathrm{mol} / 1$ dNTPs (Pharmacia), and 1 U Taq polymerase ("Amplitaq", Perkin Elmer). "Hot start" PCR amplification was used with a temperature profile of five minutes at $94^{\circ} \mathrm{C}$, followed by 30 cycles of $94^{\circ} \mathrm{C}$ for one minute, $60^{\circ} \mathrm{C}$ for one minute, $72^{\circ} \mathrm{C}$ for one minute, followed by a final extension at $72^{\circ} \mathrm{C}$ for 10 minutes. PCR products (typically $12 \mu \mathrm{l}$ ) were separated on $0.8 \%$ agarose minigels and visualised by ethidium bromide staining and UV illumination.

\section{Results}

This test provides differential molecular diagnosis of PWS and AS. PWS samples are expected to give SNRPN specific PCR products after only NotI digestion, AS after only $M c r B C$ digestion, and unaffected control DNA is expected to yield products after both $N o t \mathrm{I}$ and $M c r B C$ digestion.

The test was evaluated on 60 genomic DNA samples, 20 each from patients with PWS and AS and 20 unaffected controls. The evaluation was performed with the disease status of each sample unknown to the operator. The methylation status of all 60 samples was scored correctly giving a test specificity of $100 \%$ and sensitivity (for PWS and AS caused by deletion or UPD15) also of $100 \%$. Representative examples are shown in fig 1 .

\section{Discussion}

We have developed a rapid, PCR based test for differential molecular diagnosis of Prader-Willi and Angelman syndromes. This test makes use of two restriction endonucleases with mutually exclusive methylation requirements to analyse the imprinted methylation status of the SNRPN promoter. NotI is methylation sensitive and $M c r B C$ has an absolute requirement for methylated substrate DNA ( $M c r B C$ is the only commercially available enzyme we are aware of with such a requirement). The 1088 bp PCR product encompasses the SNRPN promoter and first exon. This region includes $23 \mathrm{CpG}$ dinucleotides, more than $96 \%$ of 
which are methylated $\left({ }^{\mathrm{m}} \mathrm{CpG}\right)$ on maternally inherited chromosomes and effectively none of which are methylated on paternal chromosomes. $^{21}$ Seventeen of these $23 \mathrm{CpG}$ dinucleotides are immediately preceded by $\mathrm{A}$ or $\mathrm{G}$ and are therefore potential substrates for McrBC (recognition site: $\mathrm{Pu}^{\mathrm{m}} \mathrm{C}\left[\mathrm{N}_{40-2000}\right] /\left[\mathrm{N}_{40 \text { - }}\right.$ $\left.{ }_{2000}\right] \mathrm{Pu}^{\mathrm{m}} \mathrm{C}$ ). Four imprinted $\mathrm{CpGs}$ lie within NotI sites (recognition sequence GC/ GGCCGC). These observations suggest that this novel test should be highly specific and sensitive for PWS and AS resulting from deletion, UPD15, or imprinting mutations. Our results support this since we were able correctly to diagnose the disease status of all 60 PWS, AS, or control samples.

Two groups have recently published PCR based methods of differential molecular diagnosis of PWS and AS. ${ }^{19}$ In both methods, patient genomic DNA was treated with sodium bisulphite (which converts unmethylated cytosine to uracil but does not modify methylated DNA) followed by PCR with primers specific to either the maternal or paternal alleles. In both reports, these methods correctly identified PWS, AS, or normal DNA in blinded analysis of samples of previously determined genotype.

The bisulphite based methods and our own method reported here appear to be completely effective at differentially diagnosing PWS and AS; however, each approach has potential advantages and disadvantages. Our method, based on differential restriction digestion, involves fewer technical steps than the reported bisulphite based tests and will be a familiar technique in molecular genetics laboratories. In addition, the published bisulphite based methods require PCR with either three ${ }^{19}$ or four ${ }^{20}$ allele specific primers, increasing start up costs compared with our method.

There is the potential for incorrect typing with either approach. In the case of the bisulphite based methods there is the potential for preferential PCR amplification of smaller (paternal) alleles producing a false diagnosis of Angelman syndrome. The most important potential problem associated with our method is that of false negatives resulting from incomplete restriction digestion. In particular, some laboratories are known to observe partial restriction digestion with NotI in Southern blot hybridisation studies (although we have not encountered this problem). Partial NotI digestion is more likely to be a problem with Southern analysis where typically $5-10 \mu \mathrm{g}$ of genomic DNA is digested than with the PCR protocol reported here where only $500 \mathrm{ng}$ or less of genomic DNA is digested. However, a false PCR signal could potentially be seen if only a very small proportion of the NotI treated target molecules remain intact (although in such cases we might expect to observe band intensity differences between the normal control and partially NotI digested AS patient DNA). Our protocol aims to minimise the likelihood of partial digestion by treating $500 \mathrm{ng}$ genomic DNA with 20 units of NotI overnight (approximately 16 hours). This should represent a significant overdigestion. In addition, alongside each batch of patient samples, PWS, AS, and normal control DNA are analysed which should allow detection of partial digestion by either enzyme.

Despite these potential sources of error, both the bisulphite methods and our Not $\mathrm{I} / M c r B C$ method present substantial advantages over previous techniques. Only a formal and blinded evaluation of both PCR based techniques on a common reference set of patient samples will indicate which (if any) of these PCR based assays will become the method of choice.

The test reported here will miss AS patients with UBE3A mutations and the very small proportion of PWS or AS patients with chromosomal abnormalities involving 15q11q13. In addition, the test will not distinguish deletions from UPD15 or imprinting mutations. However, it will confirm diagnosis in the great majority of PWS and AS cases and is rapid, non-isotopic, requires a minimal blood sample from the affected child, and does not require parental samples. These features represent substantial advantages over existing approaches (Southern blot, microsatellite analysis, or FISH) and will make this test suitable as the initial screening step in a general diagnostic strategy to confirm or exclude a clinical diagnosis of Prader-Willi or Angelman syndromes.

Both authors contributed equally to this work. We thank Dr Karin Buiting of Institut für Humangenetik, Essen, Germany for kindly providing the SNRPN nucleotide sequence

1 Knoll JHM, Nicholls RD, Magenis RE, Graham JM Jr Lalande M, Latt SA. Angelman and Prader-Willi syndromes share a common chromosome 15 deletion but differ in parental origin of the deletion. Am $\mathcal{F}$ Med Gene 1989;32:285-90

2 Robinson WP, Bottani A, Yagang X, et al. Molecular cytogenetic, and clinical investigations of Prader-Willi syndrome patients. Am f Hum Genet 1991;49:1219-34.

3 Cassidy SB, Forsythe M, Heeger S, et al. Comparison of phenotype between patients with Prader-Willi syndrome due to deletion $15 \mathrm{q}$ and uniparental disomy 15. Am $7 \mathrm{Med}$ Genet 1997;68:433-40.

4 Malcolm S, Clayton-Smith J, Nichols M, et al. Uniparental paternal disomy in Angelman's syndrome. Lancet 1991 ; 337:694-7.

5 Clayton-Smith J, Webb T, Pembrey ME, Nichols $M$ Malcolm S. Maternal origin of deletion 15q11-13 in Mal25 cases of Angelman syndrome. Hum Genet 1992;88: $25 / 25$
$376-8$.

6 American Society of Human Genetics/American College of Medical Genetics Test and Technology Transfe Committee. ASHG/ACMG Report. Diagnostic testing for Prader-Willi and Angelman syndromes: report of the ASHG/ACMG Test and Technology Transfer Committee. Am F Hum Genet 1996;58:1085-8.

7 Nicholls RD, Knoll JHM, Butler MG, Karam S, Lalande M. Genetic imprinting suggested by maternal heterodisomy in non-deletion Prader-Willi syndrome. Nature 1989;342 281-5

8 Glenn CC, Nicholls RD, Robinson WP, Saitoh S, Niikawa N, Schinzel A. Modification of 15q11-q13 DNA methylation imprints in unique Angelman and Prader-Willi patients. Hum Mol Genet 1993;2:1377-82.

9 Reis A, Dittrich B, Greger V, Lalande M, et al. Imprinting Reis A, Dittrich B, Greger V, Lalande M, et al. Imprinting
mutations suggested by abnormal DNA methylation patterns in familial Angelman and Prader-Willi syndromes. patterns in familial Angelman and

10 Sutcliffe JS, Nakao $M$, Christian $S$, et al Deletions of a differentially methylated CpG island at the SNRPN gene ferentially methylated CpG island at the SNRPN gene
define a putative imprinting control region. Nat Genet

11 Buiting K, Saitoh S, Gross S, et al. Inherited microdeletions in the Angelman and Prader-Willi syndromes define an imprinting centre on human chromosome 15. Nat Gene 1995;9:395-400.

12 Schulze A, Hansen C, Skakkebaek NE, Brondum-Nielsen K, Ledbetter DH, Tommerup N. Exclusion of SNRPN as a major determinant of Prader-Willi syndrome by a translocation breakpoint. Nat Genet 1996;12:452-4.

13 Kishino $T$, Lalande $M$, Wagstaff J. UBE3A/E6-AP mutations cause Angelman syndrome. Nat Genet 1997;15: $70-3$. 
14 Matsuura T, Sutcliffe JS, Fang $P$, et al. De-novo truncating mutations in E6-AP ubiquitin-protein ligase gene (UBE3A) in Angelman syndrome. Nat Genet 1997;15:74 7.

15 Glenn CC, Porter KA, Jong MTC, Nicholls RD, Driscoll DJ. Functional imprinting and epigenetic modification DJ. Functional imprinting and epigenetic modification 2 .

16 Glenn CC, Saitoh S, Jong MTC, et al. Gene structure, DNA methylation, and imprinted expression of the human SNRPN gene. Am $\mathrm{f}$ Hum

17 Dittrich B, Robinson WP, Knoblauch $\mathrm{H}$, et al. Molecular diagnosis of the Prader-Willi and Angelman syndromes by detection of parent-of-origin specific DNA methylation in 15q11-13. Hum Genet 1992;90:313-15.

18 Wevrick R, Francke U. Diagnostic test for the Prader-Will syndrome by SNRPN expression in blood. Lancet 1996; 348:1068-9.

19 Zeschnigk M, Lich C, Buiting K, Doerfler W, Horsthemke B. A single-tube PCR test for the diagnosis of Angelman and Prader-Willi syndrome based on allelic methylation . 94-8.

20 Kubota T, Das S, Christian SL, Baylin SB, Herman JG, Ledbetter DH. Methylation-specific PCR simplifies im-

21 Zeschnigk M, Schmitz B, Dittrich B, Buiting K, Horsthemke B, Doerfler W. Imprinted segments in the human genome: different DNA methylation patterns in the Prader-Willi/Angeman syndrome region as determined by the genomic sequencing method. Hum Mol Genet 1997;6: 387-95. 